\title{
http://doi.org/10.15359/ree.2002-2.2
}

\section{USOS DE LA TECNOLOGÍA EN EDUCACIÓN}

\author{
Lic. José Fabio Hernández Díaz(*)
}

Los recursos tecnológicos contemporáneos suelen considerar un fin y no un medio para lograr una mayor calidad del sistema educativo. A la luz de las reflexiones de Shaff y Gimeno Sacristán, el autor estructura interrogantes acerca del papel que juega la máquina en los procesos de enseñanza-aprendizaje, asi como sus aciertos, limitaciones e inconvenientes. De esta manera, nos lleva a replantearnos la posibilidad de un nuevo enfoque pedagógico fundamentado en la tecnología educativa.
Contemporary technological resources seem to be considered an end rather than a means toward the accomplishment of a greater quality education. Based on Shaff's and Gimeno Sacristán's thinking, the author raises questions around the role technology plays in the teaching-learning process, its strengths, limitations and inconveniences. He leads us to think about a new pedagogical approach founded on educational technology.

* Licenciado en la Enseñanza de la Matemática y Máster en Educación, con énfasis en docencia universitaria en el CIDE. Labora como profesor en la Escuela de Matemática del Instituto Tecnológico de Costa Rica, con una jomada de tiempo completo y en la División de Educología del CIDE. E-mail: josefabio14@latinmail.com 


\section{La acción educativa apoyada en la reflexividad}

La educación es un campo del conocimiento que requiere de constante reflexión por parte del docente. Es posible que un educador tenga una gran habilidad en algunos aspectos prácticos de su desempeño como lo son: el manejo de grupos, su expresión oral o la elaboración de materiales educativos, pero sin una concepción amplia sobre el significado de su labor, es poco el efecto que podrá lograr en el desarrollo individual y social de sus alumnos.

Se necesita una adocuada guía de la labor educativa. GimenoSacristán (1998: 54) afirma que "La reflexión como cualidad de la buena practica, como mecanismo de análisis y mejora de la misma, como ejexcicio para la formación y perfeccionamiento de los profesores, rescata a la enseñanza del ámbito de las prácticas improvisadas del de la técnica de valor universal para cualquier situación práctica". Más adelante, este mismo autor agrega "la reflexión supone el ejercicio de la capacidad cognitiva para analizar, diseñar y evaluar las acciones en contextos determinados, y su utilidad moral para discernir el valor y el significado que tienen".

El educador necesita tener una visión holística del proceso educativo, de modo que emplee la tecnología como un eslabón más de dicho proceso, tal como lo plantea Picado (1998: 39) "la pérdida de una visión totalizadora de los problemas ha sido la causa principal de las consecuencias negativas, que en el mundo modemo han traído muchas actuaciones tecnologicas".

La formación pedagógica le brinda al educador perspectiva, claridad, capacidad de discriminación y buen juicio, aspectos que son fundamentales al pretender usar la tecnología como parte de su labor docente. Al comparar el trabajo del educador con el manejo de una bicicleta, Gimeno Sacristán (1998: 68) afirma que el conocimiento práctico es necesario para sostenerse pedaleando, el que sabe las reglas puede mejorar más fácilmente y con más rendimiento el pedaleo. Y, desde luego, lo más importante sería saber hacia dónde se camina, cuál es la ruta más adecuada y por qué se elige esa dirección".

\section{Incorporación de la tecnología en los procesos educativos}

Cada nuevo descubrimiento tecnologico trae consigo oportunidades y amenazas para la humanidad. Los nuevos sistemas de información, las telecomunicaciones, los "robots inteligentes" y muchas otras innovaciones constituyen para Shaff (1985: 26) "la segunda revolución de la ciencia y la tecnología. La segunda revolución, la que estamos presenciando ahora, consiste en que el poder intelectual del hombre se ve amplificado e incluso sustituido por autómatas, los cuales eliminan con éxito creciente el trabajo humano de la producción y los servicios". Peligros como la estandarización del pensamiento, 
la eliminación de la pureza cultural y lingüística de nuestros países, el desempleo y otros son reales.

Debemos pues, asumir la tecnología con precaución, con inteligencia y no caer en la trampa de creer que ella representa la solución a todos los problemas de la humanidad y en particular de la educación. Muchos educadores depositan expectativas exageradas en la tecnología y sobrevaloran su papel, situándolo por encima de cuestiones medulares como los fines de la educación, es decir "para qué se enseña".

En el otro extremo encontramos a los educadores que rechazan a priori las nuevas tecnologías, sobre todo aquellas que no han conocido desde niños y no han incorporado a su vida personal y profesional. Ellas les hacen sentir amenazada su función tradicional en este mundo, aunque este hecho signifique ignorar la cambiante realidad que los rodea y sobre todo alejarse de la experiencia diaria de sus jóvenes estudiantes.

La postura inteligente, será pues, la que nos motive a informarnos sobre las nuevas tecnologías educativas, a conocer y comprender sus ventajas para explotarlas, sus limitaciones e incovenientes, para minimizarlos y sobre todo las transformaciones sociales que ellas nos pueden ayudar a alcanzar.

El proceso de incorporar la tecnología a la educación es muy lento y polémico. Los sistemas educativos muestran tendencias muy conservadoras, las metodologías actuales no difieren mucho de las empleadas hace muchos años, pues se han considerado de gran eficacia.

Por otro lado, las innovaciones tecnológicas, tampoco pueden incorporarse al sistema educativo en forma automática, por el contrario, como se mencionó en la parte inicial de este artículo, este proceso exige una profunda reflexión epistemológica.

Los educadores, antes de incorporar cualquier innovación tecnológica además del mayor conocimiento posible de la misma, deberán tener un panorama amplio sobre el sistema educativo en el que se pretende emplear dicha tecnología, esto incluye aspectos como los fines educativos, los contenidos disciplinarios, los alumnos, las autoridades institucionales y otros. Asimismo deberá tomar en cuenta el entorno en el que está inmerso dicho sistema educativo, efectuando un análisis de sus aspectos sociales, culturales, económicos y políticos.

\section{La tecnología educativa y su nuevo enfoque pedagógico}

Molina (1999: 4) afirma que la vigencia del conductismo como paradigma tradicional y convencional en los sistemas educativos de los diferentes países, ha empezado a ser cuestionado por especialistas en educación. De acuerdo con 
sus planteamientos, es innegable que el constructivismo se perfila como el paradigma sustituto del conductismo.

Según la propuesta constructivista, aprender consiste en que el alumno desarrolle estrategias cognitivas que lo lleven a apropiarse del saber, entre ellas, explotar, descubrir y resolver problemas. De acuerdo con Zoufaly (1992: 35) "el cabal papel de la computadora en una función imaginativa y original debería ser un elemento que se entrega al estudiante para que él mismo descubra y experimente, y no el de un instrumento que se proporciona al maestro o profesor para facilitarle la enseñanza".

Podemos concluir, a partir de los planteamientos de ambos autores que la tecnología educativa está en capacidad de responder adecuadamente a las nuevas exigencias que plantean las concepciones modernas sobre la enseñanza y el aprendizaje.

Los nuevos paradigmas educativos reclaman un mayor protagonismo del estudiante, una mayor importancia de la intuición, la creatividad y la improvisación. El alumno debe acostumbrarse a tomar decisiones y a elegir caminos que a veces no sabe a dónde lo conducen. La inseguridad y la incertidumbre son condiciones que deben ser importantes en su proceso de formación.

Por otro lado, Bartolomé Pina (1990: 10) plantea que la escuela debe ser activa, entretenida y divertida, debe ser participativa y debe ser libre, más adelante agrega "¿por qué un alumno incapaz de trabajar diez minutos seguidos en una clase, se pasa horas y horas delante de un ordenador? La clave debe buscarse en la satisfacción que ofrece la actividad. Esa es la diferencia entre divertida y aburrida".

La tecnología es capaz de proporcionar ambientes de aprendizaje que promuevan ya no la memorización de la información, sino su producción es decir la creación del conocimiento. Debe, a su vez, fomentar en el alumno la búsqueda de caminos adecuados, analizar sus errores, ensayar técnicas nuevas. El error no debe ser motivo de fracaso, por el contrario, debe ser el punto de partida para un nuevo intento en busca de la solución a una situación planteada. La tecnología puede hacer sentir al alumno que es capaz de crear cosas reales, en lugar de tediosos deberes.

Un aspecto medular respecto al empleo de la tecnología en educación es el hecho de que ésta no puede insertarse y actuar educativamente por sí misma. Ella opera a partir de la inteligencia y la creatividad humanas. Por lo tanto, la presencia de los educadores continuará siendo necesaria como mediadores entre el conocimiento de la disciplina y los estudiantes. Eso sí, su función deberá revisarse, porque es evidente que quienes sigan actuando como tradicionales transmisores de información, verán desplazado su rol día a día por otras fuentes informativas más potentes, completas y dinámicas. 
Deseo, finalizar este artículo, citando a Galvis (1996: 143) quien afirma.

¿Debiéramos esperarnos a que haya computadoras en nuestras escuelas para comenzar a pensar acerca de los beneficios que pueden traer y enfrentar los retos que ellos presentan?

A decir verdad, la computación educativa no está bajo el control de los educadores. Quienes producen o distribuyen equipos y el público en general están continuamente haciendo presión para que se introduzcan computadores en educación. ¿Debiéramos esperarnos a que ellos tomen las decisiones y, entonces, simplemente sentarnos a ver qué pasa?

De nuevo, tal sería un buen camino para maximizar nuestro subdesarrollo".

\section{Referencias}

Bartolomé, A. (1990) Preparando para un nuevo modo de conocer. Barcelona. INTERNET. EUNED.

Galvis, A. (1996) Fundamentos de Tecnología Educativa. San José:

Gimeno Sacristán, J. (1998)Poderes inestables en Educación. Madrid: Morata.

Molina, Z. (1999, Julio-Diciembre) Planificación, diseño y desarrollo curricular. UMBRAL. (10), 427.

Picado, F. (1998) La Tecnología Educativa. Curso Tecnología Educativa. Heredia, Universidad Nacional.

Schaff, A. (1985) ¿Qué futuro nos aguarda?. Barcelona: Crítica.

Zougaly, F. (1992,Abril) Computadoras en la Educación. Comunicación . 6(1), 31-37. 